\title{
High-resolution MRI of intracranial large artery diseases: how to use it in clinical practice?
}

Weihai $\mathrm{Xu}^{\odot}$

To cite: Xu W. High-resolution MRI of intracranial large artery diseases: how to use it in clinical practice?. Stroke and Vascular Neurology 2019;4: e000210. doi:10.1136/svn2018-000210

Received 7 November 2018 Revised 13 May 2019 Accepted 14 May 2019 Published Online First 20 June 2019

Check for updates

(c) Author(s) (or their employer(s)) 2019. Re-use permitted under CC BY-NC. No commercial re-use. See rights and permissions. Published by BMJ.

Department of Neurology, Peking Union Medical College Hospital, Chinese Academy of Medical Sciences, Beijing, China

Correspondence to

Dr Weihai Xu;

xuwhpumch@qq.com

\section{ABSTRACT}

High-resolution MRI (HRMRI) has emerged as a useful tool for clinical research in recent years. Compared with traditional cranial and vessel imaging, HRMRI provides more additional valuable pathophysiology information that is helpful for the differential diagnosis of intracranial atherosclerosis, dissection and vasculitis. However, there are some points that a neurologist should keep in mind. First, although enhanced vessel wall imaging is widely applied for research purposes, it is not appropriate for routine clinical use. Any injury or inflammation within vessel wall can result in enhancement, which is unspecific for a diagnosis. Second, although plaque components identified on HRMRI arouse researchers' interest, they may have limited positive predictive value for future stroke. Ruptured plaques may have higher prevalence in asymptomatic patients than expected. More prospective observational studies are required. Third, the vessel wall morphology features remain the useful and reliable clue for a diagnosis. It is true that eccentric vessel wall lesions most likely represent atherosclerosis if vessel dissection is easily excluded. For concentric wall lesions, however, the underlying pathophysiology is complicated, either atherosclerotic or non-atherosclerotic. Fourth, HRMRI can show luminal thrombus directly and provide valuable details. All in all, when HRMRI is used by a neurologist, it should not be viewed as the only key for a diagnosis. The diagnosis should be made based on patient history, lab works, other imaging technique and even genetic examinations.

In the recent years, high-resolution MRI (HRMRI) has emerged as a useful tool for clinical research. By HRMRI, intracranial vessel wall lesions can be observed in vivo. It has made it easier for the differential diagnosis of intracranial atherosclerosis (figure 1), dissection (figure 2), vasculitis (figure 3$)^{1}$ and moyamoya disease (figure 4). HRMRI can also identify intracranial luminal thrombosis. ${ }^{2}$ Compared with traditional cranial and vessel imaging, HRMRI provides more additional valuable pathophysiology information. In 2017, HRMRI has been recommended for clinical practice to differentiate the causes of intracranial arterial narrowing and identify symptomatic, non-stenotic intracranial arterial diseases by American Society of Neuroradiology. ${ }^{1}$ However, there are some points that a neurologist should keep in mind when applying this technique.

\section{VESSEL WALL ENHANCEMENT: NOT SPECIFIC}

A lot of authors believe the enhanced intracranial vessel wall imaging has good image quality and is helpful for making a diagnosis. It was reported that enhanced eccentric plaque represents vulnerable atherosclerosis and enhanced concentric wall thickening represents vasculitis. ${ }^{34}$ In patients with moyamoya disease, enhanced vessel wall lesions seldom occur. $^{5}$ However, all these opinions come from small sample size study. Any injury or inflammation within vessel wall can result in enhancement. Recent studies suggested even in healthy subjects, vessel wall can display enhancement to some extent. ${ }^{6}$ Vessel inflammation, either occurring in atherosclerosis, vasculitis or vasculopathy, has dynamic process that may have different imaging findings at different stages.

\section{PLAQUE COMPONENTS: REMAIN AWAY FROM ROUTINE CLINICAL PRACTICE}

Although fibrous caps have been observed in patients with intracranial atherosclerosis (figure 1), ${ }^{7}$ they are much thinner and have poorer image quality than those in carotid plaques. Intracranial fibrous cap fissure or rupture can be not sensitively identified by HRMRI. It is known from coronary atherosclerosis disease, ruptured plaques had higher prevalence in asymptomatic patients than expected. ${ }^{8}$ It could be assumed that the imaging findings of ruptured plaque, even identified, may have limited positive predictive value for stroke. With regard to intracranial intraplaque haemorrhage, the low prevalence suggested it is not useful marker for most patients. ${ }^{9}$

\section{VESSEL WALL MORPHOLOGY: REMAINS USEFUL}

When we observe intracranial vessel wall, the most important individual morphology 


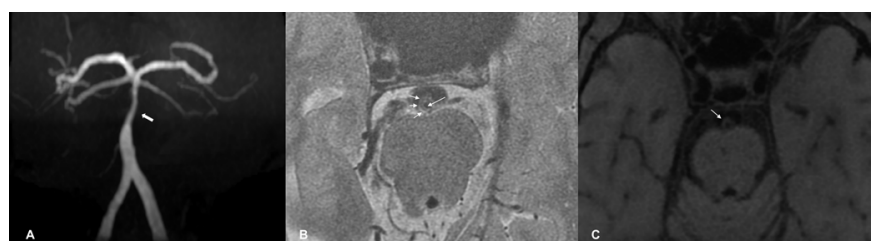

Figure 1 Magnetic resonance angiography shows basilar artery stenosis (white thick arrow (A)). On T2-weighted images of high-resolution MRI, an abnormal wall with an eccentric plaque is shown. There is a band of high signal (white long arrow (B)) adjacent to the lumen suggesting a fibrous cap, while short arrows (white short arrows (B)) indicate the outer wall boundaries of basilar artery. On the corresponding three-dimensional T1-weighted highresolution $\mathrm{MRI}$ slice, an eccentric isointense plaque is identified (white thin arrow (C)).

characteristic is eccentricity. It is true that eccentric vessel wall lesions most likely represent atherosclerosis. If a plaque develops in middle cerebral artery, it most likely locates at the ventral and inferior wall. Additional plaque components findings such as lipid core, fibrous caps and intraplaque haemorrhage may further strengthen the diagnosis. For a long stenosis, intracranial atherosclerosis may display concentric features on several image slices, but it always has at least one slice with eccentric lesion (figure 5).Different diagnosis may be required in patients with intracranial artery dissection. ${ }^{10}$ However, vessel wall haematoma at non-atherosclerosis sites is usually easier to be identified on HRMRI, as compared with other vessel imaging such as CT angiography and magnetic resonance angiography.

For concentric wall lesions, the underlying pathophysiology is complicated. They can represent atherosclerosis (usually asymptomatic), vasculitis and other non-atherosclerotic vasculopathy. ${ }^{5}$ The evidence from histological study of intracranial vessel wall lesions is very

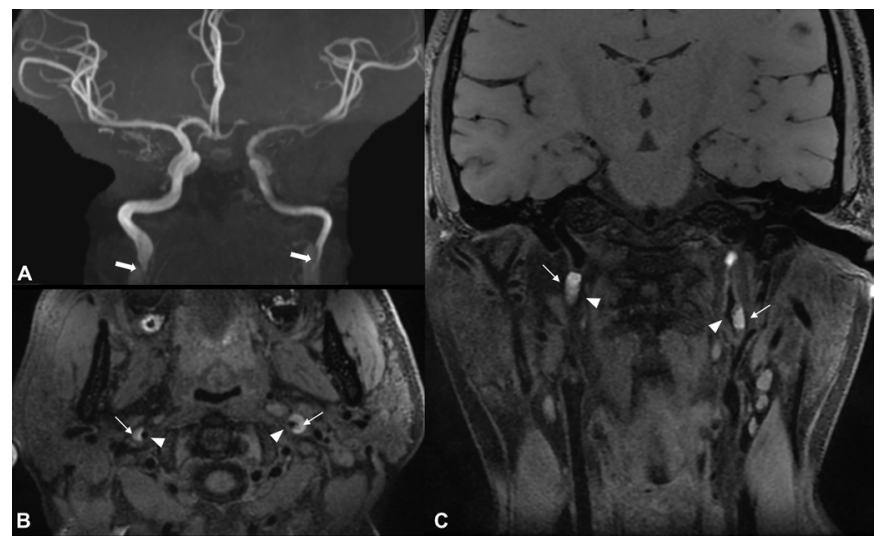

Figure 2 High-grade stenosis of bilateral internal carotid arteries (ICA) are shown on magnetic resonance angiography (white thick arrows $(A)$ ). Bilateral ICA dissections with wall haematomas are demonstrated on three-dimensional T1weighted fat-suppressed high-resolution MRI (white thin arrows indicate haematomas and white arrowheads indicates lumen (B and $\mathrm{C})$ ).

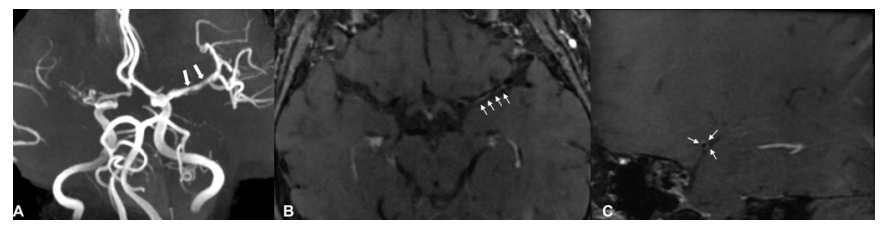

Figure 3 In a young patient with probable vasculitis, multiple segmental stenosis of left middle artery are shown on magnetic resonance angiography (white thick arrows (A)). Enhanced concentric wall thickening is seen on threedimensional contrast-enhanced T1-weighted fat-suppressed high-resolution MRI (white thin arrows (B and $\mathrm{C})$ ).

lacking. In a young patient with an intracranial concentric stenosis, it is not easy to establish the diagnosis if no clue from labwork is available. ${ }^{11}$ The pathophysiology of early asymptomatic intracranial atherosclerosis in young patients with traditional risk factors is unknown, which need further studies.

\section{LUMINAL THROMBUS: A PROMISING TOOL}

Intracranial artery clot is the main cause and therapeutic target for patients who had acute ischaemic stroke. The conventional method to evaluate the presence of a clot is the occlusion of blood flow on MRA or CTA imaging. ${ }^{12} 13$ However, it is indirect and cannot provide more accurate and useful details of thrombus. Luminal clots can be identified as hyperintense or isointense signals on non-contrast T1-weighted HRMRI in extracranial and intracranial vessels (figure 6). ${ }^{14} \mathrm{~A}$ whole picture of clot burdens including number, location, length, components, associations with other lesions and other characteristics can be clearly displayed on HRMRI, which makes it possible to investigate stroke mechanisms further. ${ }^{2}$ Although there are a small number of researches using HRMRI to study luminal clot limited to imaging technology, it will be a promising tool and wildly used in clinical practice in the future.

\section{HOW SHOULD WE USE HRMRI?}

HRMRI makes it feasible for in vivo evaluating intracranial vessel wall lesions and luminal clot. It is one of the techniques that help neurologist observe intracranial diseases. For an individual patient, HRMRI is not the only 'key'. The diagnosis should be made based on

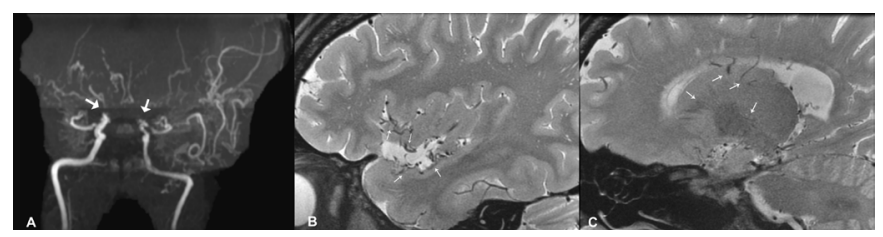

Figure 4 In a patient with moyamoya disease, bilateral internal carotid artery occlusions are shown (white thick arrows (A)). Multiple dispersed flow voids are seen in the left sylvian fissure and right basal ganglia region (white thin arrows (B and $\mathrm{C})$ ). 


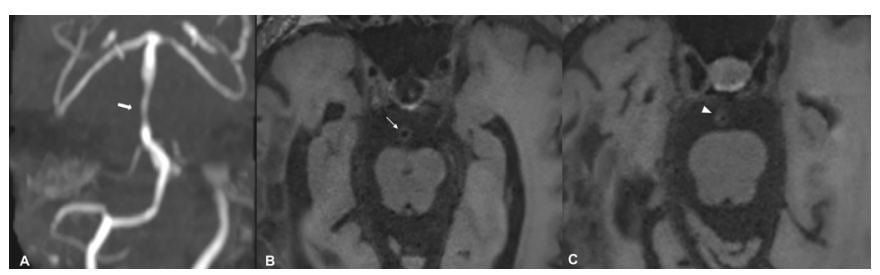

Figure 5 Magnetic resonance angiography shows basilar artery stenosis (white thick arrow (A)). On consecutive axial views of three-dimensional T1-weighted high-resolution MRI, image slices show a concentric stenosis (white thin arrow (B)) and an eccentric stenosis (white arrowhead (C)).

patient history, lab works, other imaging technique and even genetic examinations. ${ }^{15}$ It is not appropriate to give cortisone treatment simply because concentric enhanced vessel wall lesions are present on HRMRI. It is also not appropriate to give conservative treatment simply because non-enhanced eccentric asymptomatic atherosclerosis is observed. We are still far away from the 'truth' of intracranial vessel diseases even we have HRMRI now. In clinical practice, comprehensive diagnostic work should be done for making a final decision.

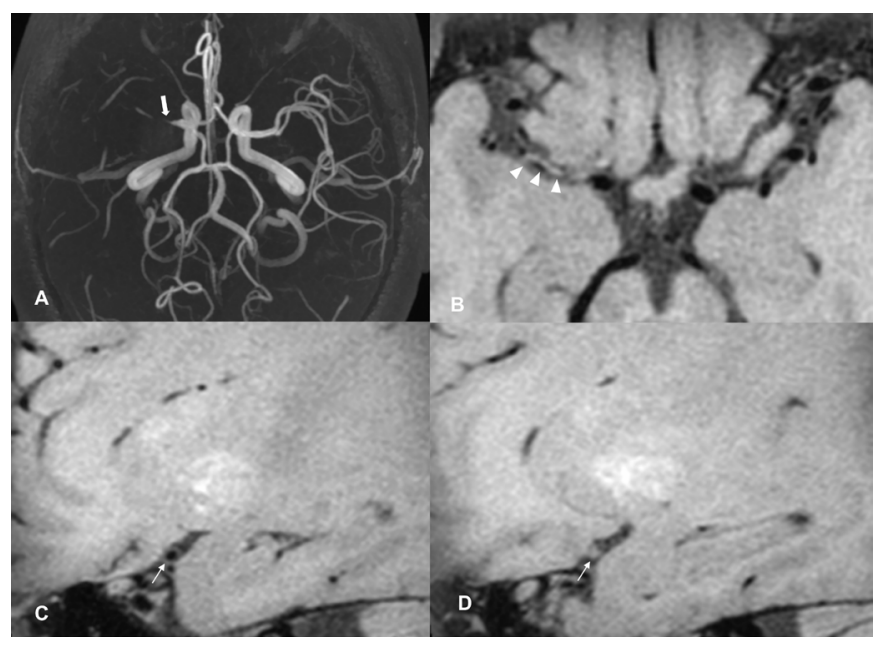

Figure 6 Magnetic resonance angiography shows right middle cerebral artery (MCA) occlusion (white thick arrow (A)). Isointense signals within the occluded MCA were noted on corresponding three-dimensional T1-weighted highresolution $\mathrm{MRI}$ (3D T1 HRMRI) images suggesting luminal thrombosis (white arrowheads (B)). On consecutive sagittal views of 3D T1 HRMRI, image slices show a normal vessel lumen (white thin arrow (C)) and an occluded vessel lumen with clots (white thin arrow (D)).
Acknowledgements The author would like to thank Qian-qian Lin for her help in editing the figures.

Contributors WX is the sole author of this manuscript.

Funding This work was supported by 2016 Peking Union Medical College Hospital Science Fund for Junior Faculty, National Natural Science Foundation of China (81671370 and 81471207).

Competing interests None declared.

Patient consent for publication Not required.

Provenance and peer review Commissioned; externally peer reviewed.

Open access This is an open access article distributed in accordance with the Creative Commons Attribution Non Commercial (CC BY-NC 4.0) license, which permits others to distribute, remix, adapt, build upon this work non-commercially, and license their derivative works on different terms, provided the original work is properly cited, appropriate credit is given, any changes made indicated, and the use is non-commercial. See: http://creativecommons.org/licenses/by-nc/4.0/.

\section{REFERENCES}

1. Mandell DM, Mossa-Basha M, Qiao Y, et al. Intracranial Vessel Wall MRI: Principles and Expert Consensus Recommendations of the American Society of Neuroradiology. AJNR Am J Neuroradiol 2017;38:218-29.

2. Xu WH, Li ML, Niu JW, et al. Luminal thrombosis in middle cerebral artery occlusions: a high-resolution MRI study. Ann Transl Med 2014;2:75.

3. Swartz $\mathrm{RH}$, Bhuta SS, Farb RI, et al. Intracranial arterial wall imaging using high-resolution 3-tesla contrast-enhanced MRI. Neurology 2009;72:627-34.

4. Gupta A, Baradaran H, Al-Dasuqi K, et al. Gadolinium Enhancement in Intracranial Atherosclerotic Plaque and Ischemic Stroke: A Systematic Review and Meta-Analysis. J Am Heart Assoc 2016;5.

5. Kim YJ, Lee DH, Kwon JY, et al. High resolution MRI difference between moyamoya disease and intracranial atherosclerosis. Eur $J$ Neurol 2013;20:1311-8.

6. Harteveld AA, van der Kolk AG, van der Worp HB, et al. Detecting Intracranial Vessel Wall Lesions With 7T-Magnetic Resonance Imaging: Patients With Posterior Circulation Ischemia Versus Healthy Controls. Stroke 2017;48:2601-4.

7. Xu WH, Li ML, Gao S, et al. In vivo high-resolution MR imaging of symptomatic and asymptomatic middle cerebral artery atherosclerotic stenosis. Atherosclerosis 2010;212:507-11.

8. Crea F, Libby P. Acute Coronary Syndromes: The Way Forward From Mechanisms to Precision Treatment. Circulation 2017;136:1155-66.

9. $\mathrm{Xu}$ WH, Li ML, Gao S, et al. Middle cerebral artery intraplaque hemorrhage: prevalence and clinical relevance. Ann Neurol 2012;71:195-8.

10. Yun SY, Heo YJ, Jeong HW, et al. Spontaneous intracranial vertebral artery dissection with acute ischemic stroke: High-resolution magnetic resonance imaging findings. Neuroradiol J 2018;31:262-9.

11. Xu YY, Li ML, Gao S, et al. Etiology of intracranial stenosis in young patients: a high-resolution magnetic resonance imaging study. Ann Transl Med 2017;5:319.

12. Dhundass S, Savatovsky J, Duron L, et al. Improved detection and characterization of arterial occlusion in acute ischemic stroke using contrast enhanced MRA. J Neuroradiol 2019.

13. Menon BK, Al-Ajlan FS, Najm M, et al. Association of Clinical, Imaging, and Thrombus Characteristics With Recanalization of Visible Intracranial Occlusion in Patients With Acute Ischemic Stroke. JAMA 2018;320:1017-26.

14. Jansen $\mathrm{CH}$, Perera $\mathrm{D}$, Makowski MR, et al. Detection of intracoronary thrombus by magnetic resonance imaging in patients with acute myocardial infarction. Circulation 2011;124:416-24.

15. Ahn SH, Lee J, Kim YJ, et al. Isolated MCA disease in patients without significant atherosclerotic risk factors: a high-resolution magnetic resonance imaging study. Stroke 2015;46:697-703. 